- Original Article

\title{
Influence of Facial Flushing on Pre- or Type 2 Diabetes Risk according to Alcohol Consumption in Korean Male
}

\author{
Jihan Kim, Jong Sung Kim*, Sung-Soo Kim, Jin-Gyu Jung, Seok-Jun Yoon, Yu-Ri Seo, Sami Lee, Yoon-Kyung Bae, \\ Won-Jin Lee \\ Department of Family Medicine, Research Institute for Medical Science, Chungnam National University School of Medicine, Daejeon, Korea
}

\section{See editorial commentary page on 137}

Background: This study aims to examine the association between alcohol consumption and the risk of pre- or type 2 diabetes mellitus (T2DM) by alcohol-induced flushing response in Korean male adults, particularly based on their body mass index (BMI).

Methods: This study selected 1,030 (158 non-drinkers, 364 flushers, and 508 non-flushers) male adults who had medical checkups. A logistic regression analysis was used to compare the association between alcohol consumption and the risk of pre- or T2DM.

Results: In both the normal-weight group (BMI $<23 \mathrm{~kg} / \mathrm{m}^{2}$ ) and the overweight group (BMI $\geq 23 \mathrm{~kg} / \mathrm{m}^{2}$ and $<25 \mathrm{~kg}$ / $\mathrm{m}^{2}$ ), the flushers had a higher risk of pre- or T2DM (odds ratio, 95\% confidence interval) when consuming more than 8 drinks of alcohol per week than the non-drinkers (normal-weight group: 3.43, 1.06-11.07; overweight group: 4.94, 1.56-15.67). But in the non-flushers among the normal-weight group and the overweight group, there was no significant difference compared to non-drinkers regarding the risk of pre- or T2DM. Obese flushers had a significantly higher risk of pre- or T2DM when consuming more than 4 drinks of alcohol per week than the non-drinkers ( $>4$ and $\leq 8$ drinks: $2.64,1.10-6.36$; $>8$ drinks: $2.42,1.11-5.27$ ). However, obese non-flushers had only a significant higher risk of pre- or T2DM when consuming more than 8 drinks of alcohol per week than the non-drinkers (2.72, 1.39-5.30)

Conclusion: These results suggest that obese flushers have an increased risk of developing pre- or T2DM even with less alcohol consumption.

Keywords: Alcohol Drinking; Flushing; Diabetes Mellitus, Type 2; Obesity

Received: July 26, 2018, Revised: August 13, 2018, Accepted: August 14, 2018

*Corresponding Author: Jong Sung Kim https://orcid.org/0000-0001-5945-0784

Tel: +82-42-280-7548, Fax: +82-42-280-7879, E-mail: josephkim@cnu.ac.kr 


\section{INTRODUCTION}

An alcohol-induced flushing response is more commonly observed in East Asian people, such as people from Korea, Japan, and Taiwan, than in Caucasian people. ${ }^{1)}$ This response is caused by the aldehyde dehydrogenase (ALDH) 2*2 variant, which is an ALDH2 enzyme involved in the metabolism of alcohol that predisposes this population to a weaker alcohol metabolic capability, causing facial flushing as a result of acetaldehyde accumulation in the body.,3)

Among Korean male drinkers, flushers, people who experience an alcohol-induced flushing response, have a higher risk of metabolic syndrome and hypertension than non-flushers, even with less alcohol consumption. ${ }^{4,5)}$ It has also been reported that flushers have an increased risk of coronary spastic angina and esophageal, pharyngolaryngeal, and bladder cancer. Hence, the clinical importance of an alcohol-induced flushing response is presently emphasized in various fields. ${ }^{6-8)}$

According to several studies, obesity plays a critical role in increasing the risk of hypertension, cardiovascular diseases, and cancers and in increasing cancer mortality rate. ${ }^{9-11)}$

Furthermore, several previous studies evaluating the effects of alcohol drinking and obesity in metabolic diseases, cardiovascular diseases, and cancers have been conducted. In Korea, a significant number of individuals are considered flushers considering their genetic features. However, most previous studies have not considered the alcohol-induced flushing response as a variable, and determining a previous study that assessed the association between alcohol drinking and obesity based on the alcohol-induced flushing response is considered difficult.

This study aims to examine the association between alcohol consumption and the risk of pre- or type 2 diabetes mellitus (T2DM) by alcohol-induced flushing response, particularly based on their body mass index (BMI).

\section{METHODS}

\section{Study Design}

This was a retrospective and cross-sectional study that was conducted in compliance with the Declaration of Helsinki. And this study was approved waiver of informed consent by the Ethics Committee of Chungnam National University Hospital (Institutional Review Board approval no., 2017-10-034-001).

\section{Study Population}

A total of 1,030 male adults who had medical checkups from October 2016 to March 2017 at a health examination center in Daejeon were selected. Individuals with the following characteristics were excluded in the study: individuals who were taking medicine after being diagnosed with diabetes mellitus and taking medicine for hypertension and hyperlipidemia that would likely affect their present lifestyle; individuals who were diagnosed with malignant tumors, cardiovascular diseases, pancreatitis, chronic hepatitis, chronic kidney disease, or pernicious anemia that would likely affect their fasting blood glucose and hemoglobin Alc (HbAlc) levels; individuals aged greater than 65 years; and individuals who responded with "I don't know" when asked whether they had facial flushing.

\section{Data Collection}

Basic data including the study subjects' past and present medical histories, medication histories, and lifestyle, including their history of alcohol drinking from their medical records that were obtained while they were having their general medical checkups, were collected. Their heights and weights were determined through body measurement, and their BMI was calculated by dividing their weight $(\mathrm{kg})$ by their height (m) squared. Based on the BMI Standard of the Asia-Pacific Region, subjects with $\mathrm{BMI}<23 \mathrm{~kg} / \mathrm{m}^{2}$ were assigned in the normalweight group, those with BMI $\geq 23 \mathrm{~kg} / \mathrm{m}^{2}$ but $<25 \mathrm{~kg} / \mathrm{m}^{2}$ were assigned in the overweight group, and those with BMI $\geq 25 \mathrm{~kg} / \mathrm{m}^{2}$ were assigned in the obese group. ${ }^{12)}$ Considering that only a few subjects $(n=12)$ with $\mathrm{BMI}<18.5 \mathrm{~kg} / \mathrm{m}^{2}$ were assigned in the low-weight group, performing an additional analysis was considered difficult. Therefore, in this study, these subjects were included in the normal-weight group.

To determine whether the subjects experienced an alcohol-induced flushing response, the following question was asked: "Do or did you experience flushing in the face immediately after drinking a glass of drink: always, sometimes, or never?" "Always," "sometimes," and "never" were used so that the study subjects could easily respond. Subjects who responded either "always" or "sometimes" were considered as flushers, while those who responded "never" were considered as nonflushers. Subjects who responded "sometimes" were considered as flushers because the sensitivity and specificity in identifying $\operatorname{ALDH} 2 * 2 / 2 * 2$ from ALDH2* $1 / 2 * 2$ as inactive ALDH2 genotypes were $96.1 \%$ and $79.0 \%$, respectively. ${ }^{13)}$

Regarding the subjects' history of alcohol drinking, the amount of alcohol that they consumed at a time and the frequency of drinks they had per week were assessed. Based on the National Institute on Alcohol Abuse and Alcoholism standard in the United States, a standard drink contains $14 \mathrm{~g}$ of alcohol. ${ }^{14)}$ This $14 \mathrm{~g}$ of alcohol can vary depending on the type of alcoholic beverage and would be $90 \mathrm{~mL}$ of $20 \%$ soju (a quarter of a soju bottle), the most popular Korean rice liquor, 12 ounces of beer (a can of beer), $45 \mathrm{~mL}$ of hard liquor (a hard-liquor glass), $150 \mathrm{~mL}$ of wine (a wine glass), and $300 \mathrm{~mL}$ of $6 \%$ makgeolli (a bowl), a traditional Korean rice liquor. The weekly average alcohol intake was calculated by multiplying the number of drinks the subjects had per week by the amount of alcohol they consumed at a time.

Regarding the subjects' smoking status, those who had never smoked before the medical checkup were classified as non-smokers, those who had smoked before but had not smoked for the past month were classified as past smokers, and those who were still smoking while taking the medical checkup or had stopped smoking less than a month ago were classified as present smokers. Based on the standard of the American College of Sports Medicine, subjects who performed 


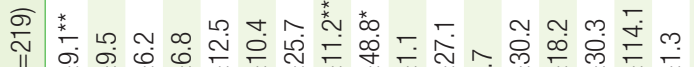

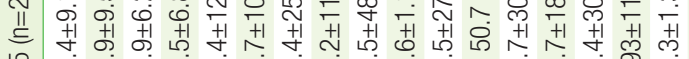

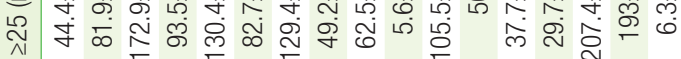

$\bar{\infty}=$

$=\overline{\mathrm{c}}$

e下竞

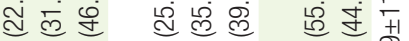

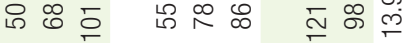

总

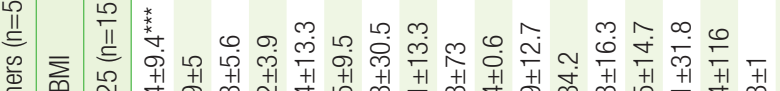

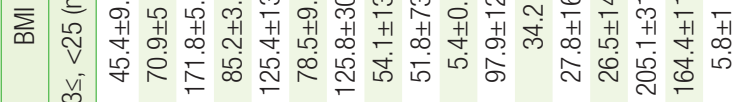

产

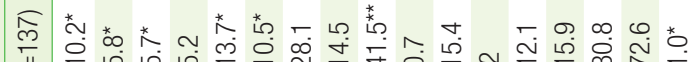

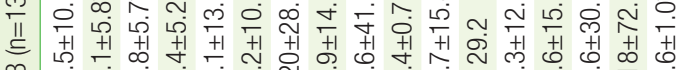

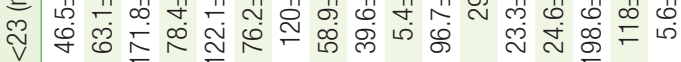

त $\overline{\mathrm{s}}$

लें क्ले लि

守称

बळ

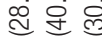

중

E $\stackrel{\infty}{\stackrel{\infty}{+}+1}$

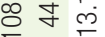

ธo

迆

峞 $₹ 8$

ब

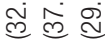

㫨的字

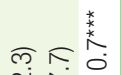

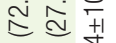

\& $\stackrel{\infty}{\circ} \circ$

至

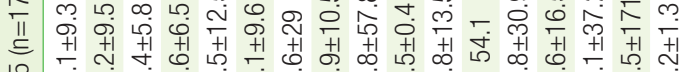

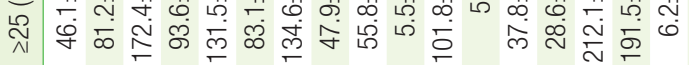

F

过守然

₹ 85

$\tilde{=} \bar{\infty}$

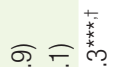

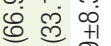

든

क्ष

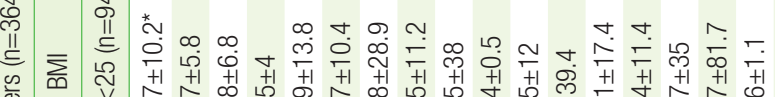

要

vi

ธก. ซิ

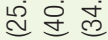

స

员的点

(1)

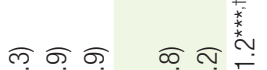

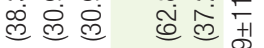

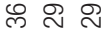

요용

व)

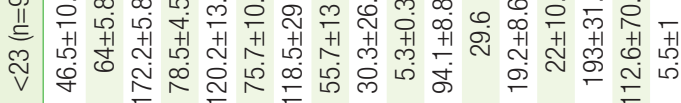

$0 \leqslant$

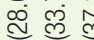

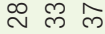

$\kappa$

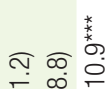

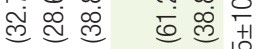

잉 $\stackrel{\infty}{\sim}$ ○

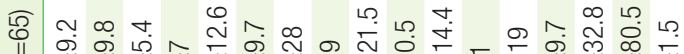

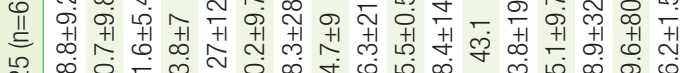

乔

क ते

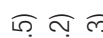

过氖

므

$\bar{\sim} \leftarrow \bar{N}$

ब

过 簋。

Ұ

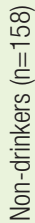

至

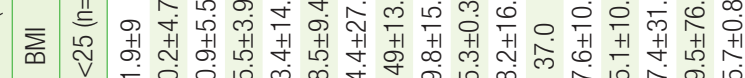
vĩ

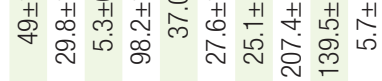

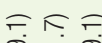

ब.

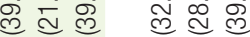

$\stackrel{\infty}{\sim} ㅇ ㅡ \stackrel{\infty}{\sim} \stackrel{\infty}{\sim} \stackrel{\infty}{\square}$

$\sigma$

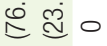

낭

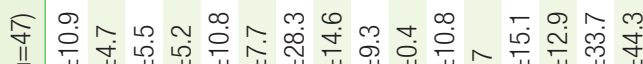

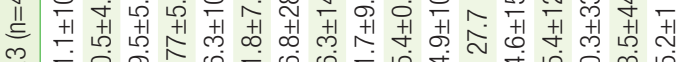

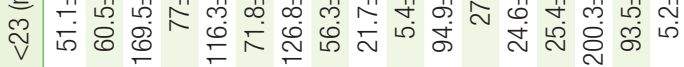

बा

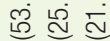

$\stackrel{2}{2}$ 우

(1)

(1)

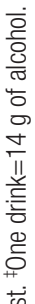

峁

$\frac{\bar{m}}{\frac{7}{2}}$

흥

क्ष

要

를 
moderate exercise for over 30 minutes at a time 5 times a week or highintensity exercise for over 20 minutes at a time 3 times a week were assigned in the regular-exercise group, those who performed exercise but did not meet the regular exercise standard were assigned in the irregular-exercise group, and the rest of the subjects were assigned in the non-exercise group. ${ }^{15)}$ Regarding the subjects' dietary habits, those who had three meals a day were assigned in the regular-eating group and those who had fewer than three meals a day were assigned in the irregular-eating group.

\section{Definition of Pre- or Type 2 Diabetes Mellitus}

This study used the examination results of the general medical checkup for the blood test values, including fasting blood glucose and HbAlc. Pre- or T2DM was diagnosed based on the diabetes diagnostic criteria of the American Diabetes Association. ${ }^{16)}$ Pre- or T2DM was determined when $\mathrm{HbAlc}$ and fasting blood glucose levels were $\geq 5.7 \%$ and $\geq 100 \mathrm{mg} / \mathrm{dL}$, respectively.

\section{Statistical Analysis}

After dividing all flushers and non-flushers into three groups, the normal-weight group, overweight group, and obese group, this study compared the flushers' and non-flushers' general characteristics, body measurements, and blood test results with those of the non-drinkers. Analysis of variance was used to analyze the continuous variables, and a chi-square test was used to analyze the categorical variables such as the years of smoking, exercise habits, and dietary habits.

After dividing all flushers and non-flushers into three weight groups and dividing their weekly average alcohol intake into three categories ( $\leq 4$ drinks, $>4$ and $\leq 8$ drinks, and $>8$ drinks), this study compared the association between alcohol intake and the risk of pre- or T2DM in the flushers and non-flushers and non-drinkers through binary logistic regression analysis. Model 1 presents the results with no modifications; model 2 presents the results with changes in age and BMI, which were highly associated with T2DM; and model 3 presents the results with changes to the total cholesterol level, smoking status, exercise status, and diet status, which may affect the risk of T2DM, including the results of model 2. The statistical level of significance was set as P-value $<0.05$, and all the statistic values were processed using the PASW SPSS ver. 18.0 (SPSS Inc., Chicago, IL, USA).

\section{RESULTS}

\section{Characteristics of the Study Subjects}

Of the 1,030 study subjects, there were 158 non-drinkers, 354 flushers, and 508 non-flushers. There were 47 non-drinkers, 98 flushers, and 137 non-flushers in the normal-weight group and 46 non-drinkers, 94 flushers, and 152 non-flushers in the overweight group. There were 65 non-drinkers, 172 flushers, and 219 non-flushers in the obese group.

The average alcohol intake per week was higher in the non-flushers than in the flushers, and the corresponding gamma-glutamyltransferase level was higher in the non-flushers than that in the flushers. However, the proportion of pre - or T2DM was higher in the flushers than in the non-flushers by each BMI group (Table 1).

\section{Distributions of Pre- or Type 2 Diabetes Mellitus according to Alcohol Intake by Facial Flushing}

In the normal-weight group, when the weekly average alcohol intake was fewer than 4 drinks, the proportions of pre- or T2DM were $23.3 \%$ in the flushers and $27.4 \%$ in the non-flushers. When more than 4 drinks and fewer than 8 drinks of alcohol were consumed on average per week, the flushers and the non-flushers had the proportions of $27.3 \%$ and $31.8 \%$, respectively. Moreover, when consuming more than 8 drinks of alcohol, the proportions were $44.4 \%$ and $30.2 \%$ for the flushers and the non-flushers, respectively.

In the overweight group, when the weekly average alcohol intake was fewer than 4 drinks, the proportions of pre- or T2DM were $23.3 \%$
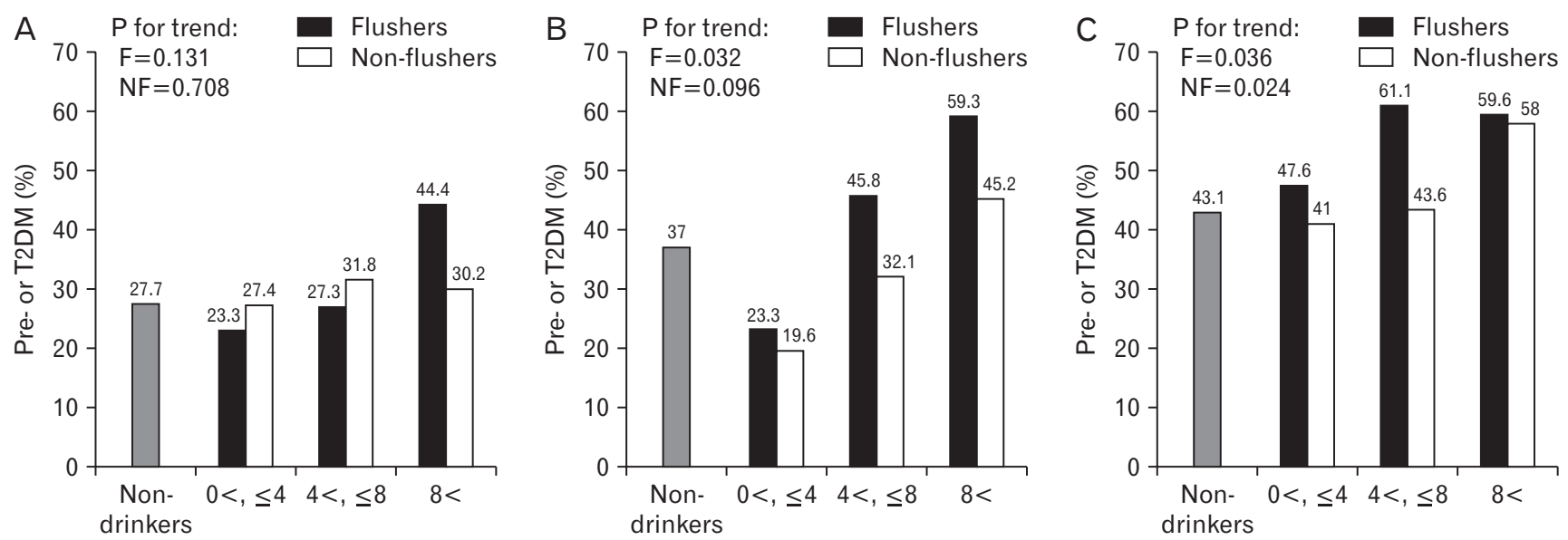

Figure 1. Proportion of pre- or T2DM according to weekly drinking amounts of flushers and non-flushers with normal-weight (A), overweight (B), and obesity (C). Each drinking group showed statistically no significant differences in terms of pre- or T2DM proportion compared to the non-drinkers. F, flushers; NF, non-flushers; T2DM, type 2 diabetes mellitus. 
in the flushers and $19.6 \%$ in the non-flushers. When consuming more than 4 drinks and fewer than 8 drinks of alcohol on average per week, the flushers and the non-flushers had the proportions of $45.8 \%$ and $32.1 \%$, respectively. Furthermore, when consuming more than 8 drinks of alcohol, the proportions were $59.3 \%$ and $45.2 \%$ for the flushers and the non-flushers, respectively.

In the obese group, when the weekly average alcohol intake was fewer than 4 drinks, the proportions of pre- or T2DM were $47.6 \%$ in the flushers and $41.0 \%$ in the non-flushers. When consuming more than 4 drinks and fewer than 8 drinks of alcohol on average per week, the flushers and the non-flushers had the proportions of $61.1 \%$ and $43.6 \%$, respectively. Moreover, when consuming more than 8 drinks of alcohol, the proportions were $59.6 \%$ and $58.0 \%$ for the flushers and the non-flushers, respectively.

There was no statistically significant difference between the drinking group and the non-drinkers by each BMI group. However, in the overweight group, the proportion of pre- or T2DM increased as the average alcohol intake per week increased in the flushers ( $P$ for trend $=0.032$ ). Moreover, in the obese group, the proportion increased as the average alcohol intake per week increased in both the flushers ( $\mathrm{P}$ for trend $=0.036$ ) and the non-flushers ( $\mathrm{P}$ for trend=0.024) (Figure 1).

\section{Logistic Regression Analysis on the Effect of Facial Flushing on the Risk of Pre- or Type 2 Diabetes Mellitus Based on the Weekly Average Alcohol Intake}

In the normal-weight flushers, when their weekly average alcohol intake was fewer than 4 drinks, the odds ratios (95\% confidence interval) were 0.80 (0.33-1.91), 0.94 (0.36-2.43), and 0.92 (0.34-2.48) for models 1,2 , and 3 , respectively. When the weekly average alcohol intake was more than 4 drinks and fewer than 8 drinks, the odds ratios were 0.98 (0.23-4.28), 0.88 (0.19-4.11), and $0.87(0.17-4.34)$ for models 1,2 , and 3 , respectively. There was no statistically significant difference in the risk of pre- or T2DM between the flushers and the non-flushers and the non-drinkers. However, when the weekly average alcohol intake was more than 8 drinks, the odds ratio of model 3 was 3.43 (1.0611.07), and a statistically significant difference was observed in the risk of pre- or T2DM between the flushers and the non-flushers and the non-drinkers.

In the normal-weight non-flushers, when the weekly average alcohol intake was fewer than 4 drinks, the odds ratios were 0.99 (0.42$2.31), 1.41$ (0.57-3.51), and 1.30 (0.51-3.33) for models 1,2 , and 3, respectively. When the weekly average alcohol intake was more than 4 drinks and fewer than 8 drinks, the odds ratios were 1.22 (0.41-3.67), 1.91 (0.58-6.30), and 1.91 (0.55-6.68) for models 1, 2, and 3, respectively. When the weekly average alcohol intake was more than 8 drinks, the odds ratios were $1.13(0.48-2.69), 1.56$ (0.62-3.93), and 1.55 (0.564.31) for models 1,2 , and 3 , respectively. Thus, no statically significant difference in the risk of pre- or T2DM between the flushers and the non-flushers and the non-drinkers, regardless of the weekly average alcohol intake, was observed (Table 2).

In the overweight flushers, when the weekly average alcohol intake was fewer than 4 drinks, the odds ratios were 0.52 (0.21-1.31), 0.67 (0.26-1.77), and 0.69 (0.25-1.88) for models 1, 2, and 3, respectively. All the odds ratios were relatively low, but there was no statistically significant difference between the flushers and the non-drinkers in the risk of pre- or T2DM. When the weekly average alcohol intake was more than 4 drinks and fewer than 8 drinks, the odds ratios were 1.44 (0.533.93), 1.80 (0.64-5.10), and 2.04 (0.69-6.04) for models 1, 2, and 3, respectively. Although all of these odds ratios were relatively higher than those of non-drinkers, there was no statistically significant difference between the flushers and the non-drinkers in the risk of pre- or T2DM. However, when the weekly average alcohol intake was more than 8 drinks, the odds ratios were 2.48 (0.94-6.57), 3.52 (1.23-10.06), and 4.94 (1.56-15.67) for models 1, 2, and 3, respectively. All of these odds ratios were relatively higher than those of the non-drinkers in the risk of pre- or T2DM. The results of models 2 and 3 were statistically significant.

However, in the overweight non-flushers, when the weekly average alcohol intake was fewer than 4 drinks, the odds ratios were 0.42 (0.17$1.04), 0.57$ (0.22-1.49), and 0.79 (0.29-2.20) for models 1,2 , and 3, respectively, but these were not statistically significant. When the weekly average alcohol intake was more than 4 drinks and fewer than 8 drinks, the odds ratios were $0.81(0.30-2.18), 1.14$ (0.40-3.23), and 1.19 (0.393.60) for models 1,2 , and 3, respectively, but these were not statistically significant. However, when the weekly average alcohol intake was more than 8 drinks, the odds ratios were 1.41 (0.66-3.00), 1.83 (0.824.09), and $1.86(0.80-4.29)$ for models 1,2 , and 3, respectively. Although all of these odds ratios were relatively high, these results were not statistically significant (Table 3).

In the obese flushers, when the weekly average alcohol intake was fewer than 4 drinks, the odds ratios were $1.20(0.63-2.30), 1.42(0.72-$ $2.80)$, and $1.38(0.70-2.75)$ for models 1,2 , and 3, respectively. All of these odds ratios were relatively high, but these were not statistically

Table 2. Odds ratio of alcohol consumption in subjects with normal weight $(\mathrm{BMl}<23$ $\mathrm{kg} / \mathrm{m}^{2}$ ) for the risk of pre- or type 2 diabetes mellitus

\begin{tabular}{ccc}
\hline \multicolumn{1}{c}{ Variable } & Flushers & Non-flushers \\
\hline $\begin{array}{c}\text { Non-drinkers }(\mathrm{n}=47) \\
\leq 4(\mathrm{n}=122)\end{array}$ & 1 & 1 \\
Model 1 & $0.80(0.33-1.91)$ & $0.99(0.42-2.31)$ \\
Model 2 & $0.94(0.36-2.43)$ & $1.41(0.57-3.51)$ \\
Model 3 & $0.92(0.34-2.48)$ & $1.30(0.51-3.33)$ \\
$4<$, $\leq 8(\mathrm{n}=33)$ & & \\
Model 1 & $0.98(0.23-4.28)$ & $1.22(0.41-3.67)$ \\
Model 2 & $0.88(0.19-4.11)$ & $1.91(0.58-6.30)$ \\
Model 3 & $0.87(0.17-4.34)$ & $1.91(0.55-6.68)$ \\
$>8$ ( $\mathrm{n}=80)$ & & \\
Model 1 & & $1.13(0.48-2.69)$ \\
Model 2 & $2.09(0.78-5.64)$ & $1.56(0.62-3.93)$ \\
Model 3 & $2.85(0.97-8.38)$ & $1.55(0.56-4.31)$ \\
\hline
\end{tabular}

Values are presented as odds ratio (95\% confidence interval). Model 1: crude; model 2: adjusted for age and BMl; and model 3: adjusted for age, BMI, total cholesterol level, current smoking, and exercise and eating habits.

BMI, body mass index. 
Table 3. Odds ratio of alcohol consumption in subjects with overweight (BMl $\geq 23$, $<25 \mathrm{~kg} / \mathrm{m}^{2}$ ) for the risk of pre- or type 2 diabetes mellitus

\begin{tabular}{ccc}
\hline \multicolumn{1}{c}{ Variable } & Flushers & Non-flushers \\
\hline $\begin{array}{l}\text { Non-drinkers }(\mathrm{n}=46) \\
\leq 4(\mathrm{n}=94)\end{array}$ & 1 & 1 \\
Model 1 & $0.52(0.21-1.31)$ & $0.42(0.17-1.04)$ \\
Model 2 & $0.67(0.26-1.77)$ & $0.57(0.22-1.49)$ \\
Model 3 & $0.69(0.25-1.88)$ & $0.79(0.29-2.20)$ \\
$4<, \leq 8(\mathrm{n}=52)$ & & \\
Model 1 & $1.44(0.53-3.93)$ & $0.81(0.30-2.18)$ \\
Model 2 & $1.80(0.64-5.10)$ & $1.14(0.40-3.23)$ \\
Model 3 & $2.04(0.69-6.04)$ & $1.19(0.39-3.60)$ \\
$>8$ ( $\mathrm{n}=100)$ & & \\
Model 1 & $2.48(0.94-6.57)$ & $1.41(0.66-3.00)$ \\
Model 2 & $3.52(1.23-10.06)$ & $1.83(0.82-4.09)$ \\
Model 3 & $4.94(1.56-15.67)$ & $1.86(0.80-4.29)$ \\
\hline
\end{tabular}

Values are presented as odds ratio (95\% confidence interval). Model 1: crude; model 2: adjusted for age and BMl; and model 3: adjusted for age, BMl, total cholesterol level, current smoking, and exercise and eating habits.

BMI, body mass index.

significant. However, when the weekly average alcohol intake was more than 4 drinks and fewer than 8 drinks, the odds ratios were 2.08 (0.91-4.77), 2.63 (1.10-6.31), and 2.64 (1.10-6.36) for models 1, 2, and 3 , respectively. Specifically, models 2 and 3 showed statistically significant difference. When the weekly average alcohol intake was more than 8 drinks, the odds ratios were 1.95 (0.93-4.09), 2.41 (1.11-5.24), and 2.42 (1.11-5.27) for models 1, 2, and 3, respectively, with models 2 and 3 showing statistically significant difference.

In the obese non-flushers, when the weekly average alcohol intake was fewer than 4 drinks, the odds ratios were 0.92 (0.45-1.86), 1.28 (0.61-2.69), and 1.31 (0.62-2.79) for models 1,2 , and 3, respectively. When the weekly average alcohol intake was more than 4 drinks and fewer than 8 drinks, the odds ratios were 1.02 (0.46-2.28), 1.21 (0.53$2.79)$, and $1.26(0.53-2.96)$ for models 1,2 , and 3 , respectively. All odds ratios were relatively higher for the risk of pre- or T2DM in the nonflushers than those in the non-drinkers, but these were not statistically significant. However, when the weekly average alcohol intake was more than 8 drinks, the odds ratios were 1.82 (0.99-3.36), 2.36 (1.244.52), and 2.72 (1.39-5.30) for models 1,2 , and 3, respectively, in the non-flushers. Models 2 and 3 showed statistically significant results (Table 4).

\section{DISCUSSION}

After dividing all the study subjects into the normal-weight group, overweight group, and obese group, this study examined the changes in the risk of pre- or T2DM according to the weekly average alcohol intake depending on the alcohol-induced flushing response. Thus, when obese non-flushers consumed more than 8 drinks of alcohol on average per week, they had a higher risk of pre- or T2DM than the nondrinkers. In contrast, it was found that obese flushers had an increased risk of pre- or T2DM even when consuming a relatively low amount of
Table 4. Odds ratio of alcohol consumption in subjects with obesity (BMl $\left.\geq 25 \mathrm{~kg} / \mathrm{m}^{2}\right)$ for the risk of pre- or type 2 diabetes mellitus

\begin{tabular}{ccc}
\hline \multicolumn{1}{c}{ Variable } & Flushers & Non-flushers \\
\hline $\begin{array}{l}\text { Non-drinkers }(\mathrm{n}=65) \\
\leq 4(\mathrm{n}=145)\end{array}$ & 1 & 1 \\
Model 1 & & $0.92(0.45-1.86)$ \\
Model 2 & $1.20(0.63-2.30)$ & $1.28(0.61-2.69)$ \\
Model 3 & $1.42(0.72-2.80)$ & $1.31(0.62-2.79)$ \\
$4<$, $\leq 8$ ( $=75)$ & $1.38(0.70-2.75)$ & \\
Model 1 & & $1.02(0.46-2.28)$ \\
Model 2 & $2.08(0.91-4.77)$ & $1.21(0.53-2.79)$ \\
Model 3 & $2.63(1.10-6.31)$ & $1.26(0.53-2.96)$ \\
$>8$ (n=171) & $2.64(1.10-6.36)$ & \\
Model 1 & & $1.82(0.99-3.36)$ \\
Model 2 & $1.95(0.93-4.09)$ & $2.36(1.24-4.52)$ \\
Model 3 & $2.41(1.11-5.24)$ & $2.72(1.39-5.30)$ \\
\hline
\end{tabular}

Values are presented as odds ratio (95\% confidence interval). Model 1: crude; model 2: adjusted for age and BMl; and model 3: adjusted for age, BMI, total cholesterol level, current smoking, and exercise and eating habits.

BMI, body mass index.

alcohol ( $>4$ drinks/wk).

This study has the following results. First, the difference in the proportion of pre- or T2DM according to BMI in the non-drinkers is confirmed in this study. The proportions of pre- or T2DM were $27.7 \%$, $37.0 \%$, and $43.1 \%$ in the normal-weight group, overweight group, and obese group, respectively, indicating that the heavier the male adults are in weight, the higher the proportion of pre- or T2DM becomes. These results seem to indirectly support the data from the International Diabetes Federation, ${ }^{17)}$ which demonstrated that almost half of all diabetic patients (48.6\%) were diagnosed with obesity, which causes insulin resistance and hyperinsulinemia through their inflammatory responses, consequently increasing their risk of T2DM. ${ }^{18)}$ Additionally, obesity promotes intracellular pathway that causes insulin resistance inside the body and leads to a decrease in the function of the mitochondrion, ultimately lowering the function of pancreatic beta cells and increasing their resistance against insulin. As such, the results of this study seem to indirectly support the theory that obesity increases the risk of T2DM. ${ }^{19}$

Second, excessive drinking increases the risk of pre- or T2DM. In the obese non-flushers, when their weekly average alcohol intake was more than 8 drinks, their risk of pre- or T2DM was higher than for the non-drinkers. According to a meta-analysis, excessive drinking in male adults increases the relative risk of T2DM regardless of obesity. ${ }^{20)}$ Moreover, according to a Swedish study, when male adults aged 35-56 years consume over $5 \mathrm{~g}$ of alcohol per day, the risk of T2DM may increase. ${ }^{21)}$ Based on their study results and the results of this study, excessive drinking seems to increase the risk of pre- or T2DM. However, some study results have found that excessive drinking is not associated with the risk of $\mathrm{T} 2 \mathrm{DM}^{22)}$ because excessive drinkers had other underlying diseases caused by excessive drinking in several cases, such as liver cirrhosis, and had stopped drinking to treat underlying diseases, which may have been one of the main reasons why there was no difference 
between excessive drinkers and non-drinkers for the risk of T2DM.

Third, the risk of pre- or T2DM by drinking may differ depending on the alcohol-induced flushing response. In both the normal-weight and overweight groups, there was no significant difference between the non-flushers and the non-drinkers regarding the risk of pre- or T2DM. However, when the weekly average alcohol intake was more than 8 drinks for the flushers, the risk of pre- or T2DM was higher in the flushers than that in the non-drinkers; these differences between the flushers and the non-drinkers were also found in other studies. According to a previous study, when consuming the same amount of alcohol (more than 12 drinks and fewer than 20 drinks), the flushers had higher insulin resistance than the non-drinkers, but there was no significant difference between the non-flushers and the non-drinkers regarding insulin resistance. ${ }^{23)}$ According to another study, when drinking alcohol excessively, the flushers had higher HbAlc level than the non-drinkers, while the non-flushers had a decreased HbAlc level. ${ }^{24)}$ A difference in the process of glucose metabolism due to the alcoholinduced flushing response was observed possibly because during alcohol drinking, acetaldehyde is accumulated in the body, causing more oxidative stress reactions and hepatotoxicity. ${ }^{25)}$

Finally, obese flushers had a higher risk of pre- or T2DM, even when consuming little alcohol (over 4 drinks), than the non-flushers and non-drinkers. According to a previous study, when consuming as little alcohol as one or 2 drinks per day, Korean obese male adults may have an increased prevalence of impaired fasting plasma glucose or $\mathrm{T}_{2} \mathrm{DM}{ }^{26)}$ In relation to obesity and diabetes, adipose tissue plays an important role in breaking down fat and increasing insulin reactivity by producing free fatty acids. When these adipose tissues expand, hypoxia of the local tissues, infiltration of the inflammatory cells, and deformation of the intracellular pathway occur. Consequently, with obesity, free oxygen radicals suppress the signal transduction of insulin receptors. ${ }^{27)}$ According to another previous study, since inactive ALDH2 causes more oxidative stress responses, mice with inactive ALDH2 accumulate more beta amyloids through oxidative stress responses including free oxygen radicals, resulting in an increased risk of Alzheimer's disease. ${ }^{28)}$ Considering these results, the hypothesis that an excess of adipose tissues induces more free oxygen radicals in the flushers with obesity is considered logical. Hence, acetaldehyde accumulation from alcohol is observed in the obese flushers, leading to more oxidative stress responses in the body when drinking alcohol, increasing the concentration of blood glucose or insulin resistance, even leading to an increased risk of pre- or T2DM.

This study has few limitations. First, this study is a cross-sectional study. Second, it is a single-center study. Third, instead of ALDH2 genotyping, this study uses a questionnaire to assess the presence of alcohol-induced facial flushing response in the study subjects. Fourth, the present study did not perform the oral glucose tolerance test in assessing the risk of pre- or T2DM. Finally, this study did not include female study subjects.

Nevertheless, the results of this study are important in determining whether normal-weight and overweight male adults with alcohol-in- duced flushing response have an increased risk of pre- or T2DM when they consume more than 8 drinks of alcohol on average per week. Moreover, obese male flushers have a higher risk of pre- or T2DM when they consume more than 4 drinks of alcohol on average per week than the non-drinkers.

\section{CONFLICT OF INTEREST}

No potential conflict of interest relevant to this article was reported.

\section{ORCID}

Jihan Kim: https://orcid.org/0000-0003-1364-5169

Jong Sung Kim: https://orcid.org/0000-0001-5945-0784

Sung-Soo Kim: https://orcid.org/0000-0001-9417-7728

Jin-Gyu Jung: https://orcid.org/0000-0003-1400-4187

Seok-Jun Yoon: https://orcid.org/0000-0002-6784-8191

Yu-Ri Seo: https://orcid.org/0000-0001-6371-4025

Sami Lee: https://orcid.org/0000-0003-3653-7734

Yoon-Kyung Bae: https://orcid.org/0000-0003-4683-9779

Won-Jin Lee: https://orcid.org/0000-0003-3804-0166

\section{REFERENCES}

1. Wolff PH. Ethnic differences in alcohol sensitivity. Science 1972;175: 449-50.

2. Crabb DW. Ethanol oxidizing enzymes: roles in alcohol metabolism and alcoholic liver disease. Prog Liver Dis 1995;13:151-72.

3. Agarwal DP, Harada S, Goedde HW. Racial differences in biological sensitivity to ethanol: the role of alcohol dehydrogenase and aldehyde dehydrogenase isozymes. Alcohol Clin Exp Res 1981;5:12-6.

4. Jung JG, Kim JS, Kim YS, Oh MK, Yoon SJ. Hypertension associated with alcohol consumption based on the facial flushing reaction to drinking. Alcohol Clin Exp Res 2014;38:1020-5.

5. Kim MY, Kim SS, Kim JS, Jung JG, Kwon BR, Ryou YI. Relationship between alcohol consumption and metabolic syndrome according to facial flushing in Korean males. Korean J Fam Med 2012;33:211-8.

6. Mizuno Y, Harada E, Morita S, Kinoshita K, Hayashida M, Shono M, et al. East Asian variant of aldehyde dehydrogenase 2 is associated with coronary spastic angina: possible roles of reactive aldehydes and implications of alcohol flushing syndrome. Circulation 2015;131:1665-73.

7. Zhang J, Zhang S, Song Y, Ma G, Meng Y, Ye Z, et al. Facial flushing after alcohol consumption and the risk of cancer: a meta-analysis. Medicine (Baltimore) 2017;96:e6506.

8. Masaoka H, Matsuo K, Sawada N, Yamaji T, Goto A, Shimazu T, et al. Alcohol consumption and bladder cancer risk with or without the flushing response: the Japan Public Health Center-based Prospective Study. Int J Cancer 2017;141:2480-8.

9. Kim NH, Seo JA, Cho H, Seo JH, Yu JH, Yoo HJ, et al. Risk of the development of diabetes and cardiovascular disease in metabolically healthy obese people: the Korean genome and epidemiology study. Medicine (Baltimore) 2016;95:e3384.

10. DeMarco VG, Aroor AR, Sowers JR. The pathophysiology of hyperten- 
sion in patients with obesity. Nat Rev Endocrinol 2014;10:364-76.

11. Gallagher EJ, LeRoith D. Obesity and diabetes: the increased risk of cancer and cancer-related mortality. Physiol Rev 2015;95:727-48.

12. World Health Organization; International Association for the Study of Obesity; International Obesity Task Force. The Asia-Pacific perspective: redefining obesity and its treatment. Sydney: Health Communications Australia; 2000.

13. Yokoyama A, Muramatsu T, Ohmori T, Kumagai Y, Higuchi S, Ishii H. Reliability of a flushing questionnaire and the ethanol patch test in screening for inactive aldehyde dehydrogenase-2 and alcohol-related cancer risk. Cancer Epidemiol Biomarkers Prev 1997;6:1105-7.

14. Willenbring ML, Massey SH, Gardner MB. Helping patients who drink too much: an evidence-based guide for primary care clinicians. Am Fam Physician 2009;80:44-50.

15. Haskell WL, Lee IM, Pate RR, Powell KE, Blair SN, Franklin BA, et al. Physical activity and public health: updated recommendation for adults from the American College of Sports Medicine and the American Heart Association. Med Sci Sports Exerc 2007;39:1423-34.

16. American Diabetes Association. 2. Classification and diagnosis of diabetes: standards of medical care in diabetes-2017. Diabetes Care 2017;40(Suppl 1):S11-24.

17. International Diabetes Federation. IDF Diabetes Atlas. 7th ed. Brussels: International Diabetes Federation; 2015.

18. Garg SK, Maurer H, Reed K, Selagamsetty R. Diabetes and cancer: two diseases with obesity as a common risk factor. Diabetes Obes Metab 2014;16:97-110.

19. Eckel RH, Kahn SE, Ferrannini E, Goldfine AB, Nathan DM, Schwartz MW, et al. Obesity and type 2 diabetes: what can be unified and what needs to be individualized? J Clin Endocrinol Metab 2011;96:1654-63.

20. Knott C, Bell S, Britton A. Alcohol consumption and the risk of type 2 diabetes: a systematic review and dose-response meta-analysis of more than 1.9 million individuals from 38 observational studies. Diabetes Care 2015;38:1804-12.

21. Cullmann M, Hilding A, Ostenson CG. Alcohol consumption and risk of pre-diabetes and type 2 diabetes development in a Swedish population. Diabet Med 2012;29:441-52.

22. Li XH, Yu FF, Zhou YH, He J. Association between alcohol consumption and the risk of incident type 2 diabetes: a systematic review and dose-response meta-analysis. Am J Clin Nutr 2016;103:818-29.

23. Jung JG, Kim JS, Oh MK. The role of the flushing response in the relationship between alcohol consumption and insulin resistance. Alcohol Clin Exp Res 2010;34:1699-704.

24. Kuwahara K, Kochi T, Nanri A, Tsuruoka H, Kurotani K, Pham NM, et al. Flushing response modifies the association of alcohol consumption with markers of glucose metabolism in Japanese men and women. Alcohol Clin Exp Res 2014;38:1042-8.

25. Chandrasekaran K, Swaminathan K, Mathan Kumar S, Clemens DL, Dey A. In vitro evidence for chronic alcohol and high glucose mediated increased oxidative stress and hepatotoxicity. Alcohol Clin Exp Res 2012;36:1004-12.

26. Roh WG, Shin HC, Choi JH, Lee YJ, Kim K. Alcohol consumption and higher incidence of impaired fasting glucose or type 2 diabetes in obese Korean men. Alcohol 2009;43:643-8.

27. Frohnert BI, Sinaiko AR, Serrot FJ, Foncea RE, Moran A, Ikramuddin S, et al. Increased adipose protein carbonylation in human obesity. Obesity (Silver Spring) 2011;19:1735-41.

28. Ohsawa I, Nishimaki K, Yasuda C, Kamino K, Ohta S. Deficiency in a mitochondrial aldehyde dehydrogenase increases vulnerability to oxidative stress in PC12 cells. J Neurochem 2003;84:1110-7. 